\title{
Vanadium-Catalyzed Addition of Propargyl Alcohols and Imines
}

\author{
Barry M. Trost and Cheol K. Chung \\ Department of Chemistry, Stanford University, Stanford, California 94305-5080, E-mail: \\ Bmtrost@stanford.edu
}

Simple addition reactions and prototropic rearrangements are two major types of atomeconomical processes. ${ }^{1}$ More powerful and useful transformations are possible when these two classes of reactions are combined. The aldol-type addition reactions of propargylic alcohols and allenic alcohols recently developed in our group are good examples of such transformation. $^{2}$

To extend the scope of the oxovanadium-catalyzed aldol-type reaction, we considered using imines in a Mannich-type addition reaction. The inferior reactivity of imines, compared to carbonyl compounds was an apparent concern we had from the outset, because the simple Meyer-Schuster rearrangement product may prevail if the nucleophilic addition to the imines is not efficient. ${ }^{3}$ Therefore, we began our study by identifying an appropriate imine substrate for the vanadium-catalysis.

The initial screening test results with some readily accessible imines, such as $N$ - phenyl, $N$ sulfonyl, $N$-phosphorylimines, and $O$ - methyl benzyloxime, were disappointing producing only the Meyer-Schuster rearrangement product. This result indicates that although the sigmatropic rearrangement was operative, trapping of the imines was not efficient. Use of the more electrophilic $N$ - phenylglyoxaldimine resulted in a complex reaction mixture. On the other hand, the reaction with $N$-methoxycarbonylimine 3 gave the desired Mannich addition product 4 in 31\% yield along with an unusual addition product 5 in $57 \%$ yield (eq 1).

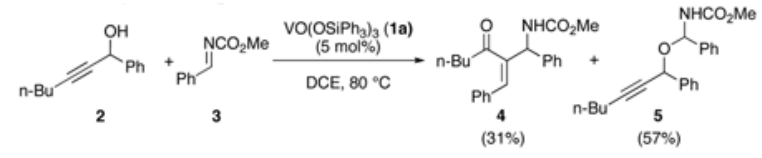

(1).

The adduct 5 is likely formed by an uncatalyzed background reaction, as was confirmed by the control experiment run in the absence of the vanadium catalyst, which provided $\mathbf{5}$ in quantitative yield. Remarkably, this aminal adduct 5 was highly stable and didn't revert to 2 and $\mathbf{3}$ even with prolonged reaction time in the presence or absence of the vanadium catalyst.

Encouraged by the somewhat promising result with $N$-methoxycarbonylimine $\mathbf{3}$, a series of optimization studies was conducted to minimize the formation of $\mathbf{5}$, varying parameters such as solvent, stoichiometry, and additives. While no other attempts were fruitful, the slow addition of 2 proved beneficial, providing the Mannich addition product 4 in 54\% yield and the simple addition product 5 in $20 \%$ yield.

We turned our attention to modifying the vanadium-catalyst with electron-withdrawing groups, which we thought would facilitate the desired addition reaction pathway by promoting the transesterification step (Scheme 1, A - C and E $\rightarrow$ C). Furthermore, the placement of electron- 
withdrawing groups on the vanadium metal center was expected to increase the Lewis acidity of the catalyst, thereby accelerating the addition step (D_E) through the activation of the imines toward electrophilic attack due to enhanced comlexation. Indeed, the transesterification was suggested as the rate-determining step for the oxovanadium-catalyzed Meyer-Schuster rearrangement. ${ }^{4}$ This is consistent with our own results obtained in the previous study of the aldehyde addition reaction in which electron-rich propargyl alcohols provided aldol-type addition product in higher yield than electron-poor propargyl alcohols.

Based on this hypothesis, we synthesized a series of oxovanadium catalysts bearing electronwithdrawing groups according to literature procedures (eq 2). ${ }^{4}$

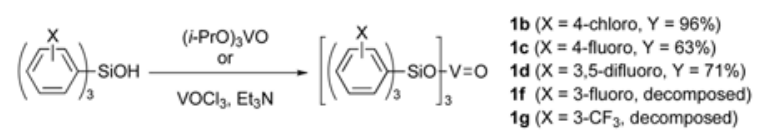

(2).

Curiously, vanadates $\mathbf{1 f}$ and $\mathbf{1} \mathbf{~ g}$ with unsymmetrically substituted arylsilanols failed to give a stable complex. On the other hand, $\mathbf{1 b}, \mathbf{1 c}$, and $\mathbf{1 d}$ were readily recrystallized and tested in the Mannich-type addition reaction with the propargylic alcohol $\mathbf{2}$ and $N$-methoxycarbonylimine 3. The results are summarized in Table 1.

To our delight, all three new catalysts performed well in suppressing the background reaction compared to the standard catalyst 1a. Among the vanadium complexes that were examined, tris[tri(4-chlorophenyl)silyl]vanadate $\mathbf{1 b}$ gave the most desirable result, providing the Mannich-type addition product $\mathbf{4}$ in $92 \%$ yield with no noticeable amount of $\mathbf{5}$. Remarkably, 1b catalyzed the desired addition reaction even without using the slow addition procedure (entry 5). In general, better results were obtained with slower addition of 2 (entries 3-5). The yield eroded when $2.5 \mathrm{~mol} \%$ of the catalyst was employed instead of $5 \mathrm{~mol} \%$ (entry 6 ). The vanadium complex 1c showed good performance as well, providing the addition product in $81 \%$ yield, using a slow addition technique (entry 8 ). On the other hand, the reaction with the complex 1d was not as clean as with the other two complexes and produced many byproducts, including the Meyer-Schuster product in $11 \%$ yield (entry 7 ).

Adopting the optimized reaction conditions used in entry 3 of Table 1 as our standard, the variation of the propargylic alcohols and imines was explored (Table 2). ${ }^{5}$ All the alcohol substrates bearing an aryl group at the propargylic position participated well in the reaction providing the Mannich-type addition product in good yield. Unlike the aldehyde addition, the effect of the electronic character of 2 was not pronounced (entries 5, 6). Imines with both electron-donating groups (entries 7,8), and electron-withdrawing groups (entry 9) gave the addition product in moderate to good yield. Imines containing heteroaromatic groups were also examined. The imine derived from furfuraldehyde gave the addition product in somewhat low yield, possibly due to the thermal instability of the imine (entry 10). On the other hand, the thiophene-containing imine gave the adduct in high yield (entry 11). The imine derived from cinnamaldehyde participated moderately well, providing the 1,2-addition product in $50 \%$ yield (entry 12).

Notably, the addition reaction produced only $Z$-enones in all examples. The complete stereoselectivity for the $Z$-olefin isomer could be explained by a staggered geometry of the allenoate structure $\mathbf{D}$ (Scheme 2). The approach from the hydrogen-substituted face (D-b), which leads to $Z$-enone product $\mathbf{F}$-b, should be favored over the approach from the arylsubstituted face (D-a) on steric grounds. 
The imine derived from pivaldehyde only led to the formation of the Meyer-Schuster product (44\%) and simple adduct (37\%). Attempts to use an enecarbamate as a 'masked' imine proved unsuccessful providing no reaction. ${ }^{6}$

To test whether the chirality of starting material was transferred to the addition product, an enantiomerically enriched propargylic alcohol 6 was prepared. ${ }^{7}$ The addition product 7 was obtained in $65 \%$ yield, but it showed virtually no enantiomeric excess, indicating that the vanadium-catalyzed addition occurred in a non-stereospecific manner under the given conditions (eq 3$)^{8}$
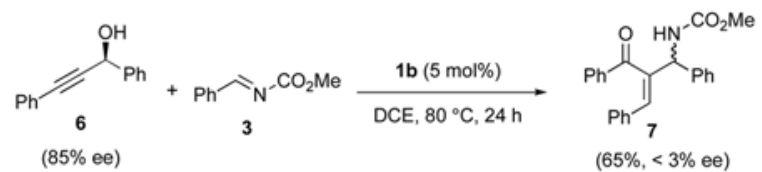

(3).

In summary, the 2-acylallylic carbamates are accessible by an atom-economic strategy from terminal acetylene, aldehyde, and $N$-acylimines by a series of addition reactions by taking advantage of the ability of oxovanadium complex to induce [3.3] sigmatropic rearrangement from propargylic alcohols. The optimized conditions were successfully applied to a range of propargylic alcohols and aromatic imines. The products of the current reaction, the $\beta$-arylsubstituted $Z$-enone compounds containing an allylic amino functionality are not readily accessible with other methods including the aza-Baylis-Hillman reaction. ${ }^{9}$

\section{Supplementary Material}

Refer to Web version on PubMed Central for supplementary material.

\section{Acknowledgements}

We thank the National Institutes of Health (GM13598) for their generous financial support. C.K.C. thanks John Stauffer Foundation and Eli Lilly \& Co. for graduate fellowship. Mass spectra were provided by the Mass Spectrometry Facility, University of San Francisco, supported by the NIH Division of Research Resources.

\section{References}

1. (a) Trost BM. Science 1991;254:1471. [PubMed: 1962206] (b) Trost BM. Angew Chem Int Ed 1995;34:259.

2. For propargyl alcohol reactions, (a) Trost BM, Oi S. J Am Chem Soc 2001;123:1230. [PubMed: 11456678]For allenic alcohol reactions, (b) Trost BM, Jonasson C, Wucher M. J Am Chem Soc 2001;123:12736. [PubMed: 11741462] (c) Trost BM, Jonasson C. Angew Chem Int Ed 2003;42:2063.

3. (a) Meyer KH, Schuster K. Chem Ber 1922;55:819. (b) Swaminat S, Narayana KV. Chem Rev 1971;71:429.

4. Pauling H, Andrews DA, Hindley NC. Helv Chim Acta 1976;59:1233.

5. The imines were prepared according to Kupfer R, Meier S, Wurthwein EU. Synthesis 1984:688.

6. Koradin C, Polborn K, Knochel P. Angew Chem Int Ed 2002;41:2535.

7. Frantz DE, Fassler R, Carreira EM. J Am Chem Soc 2000;122:1806.

8 . The nearly complete racemization indicates that the rearrangement may proceed through an ion-pair intermediate involving a propargylic cation, intead of a cyclic transition state. For a similar nonstereospecific oxometal-catalyzed transformation, see Sherry BD, Radosevich AT, Toste FD. J Am Chem Soc 2003;125:6076. [PubMed: 12785836]

9. Shi YL, Xu YM, Shi M. Adv Synth Catal 2004;346:1220. 


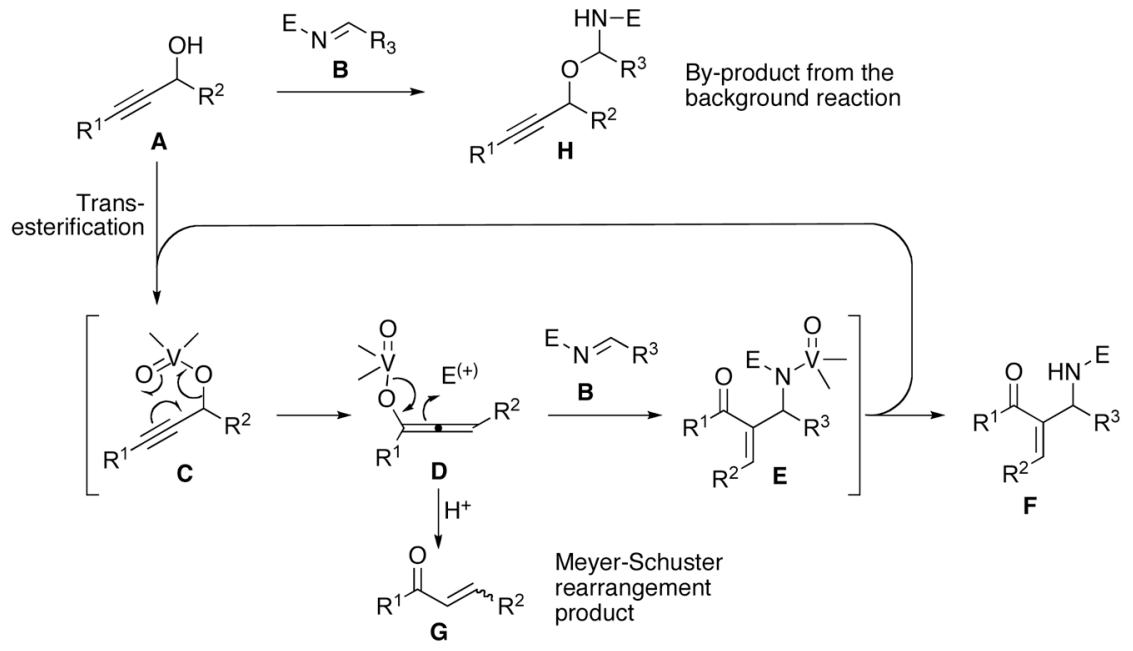

Scheme 1

Proposed Reaction Mechanism 


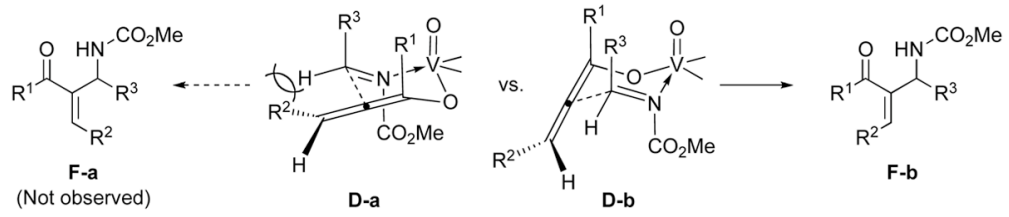

Scheme 2.

Rationale for the Z-Selectivity 
Optimization Study

Table 1

\begin{tabular}{|c|c|c|c|c|}
\hline \multirow[t]{2}{*}{ Entry } & \multirow[t]{2}{*}{ Catalyst } & \multirow[t]{2}{*}{ Conditions, ${ }^{a b}$} & \multicolumn{2}{|c|}{ Yield } \\
\hline & & & 4 & 5 \\
\hline 1 & $1 \mathbf{a}$ & A & $18 \%$ & $74 \%$ \\
\hline 2 & $1 a$ & $\mathrm{~B}(20 \mathrm{~h})$ & $54 \%$ & $20 \%$ \\
\hline 3 & $1 b$ & $\mathrm{~B}(20 \mathrm{~h})$ & $92 \%$ & -- \\
\hline 4 & $1 b$ & $\mathrm{~B}(10 \mathrm{~h})$ & $84 \%$ & -- \\
\hline 5 & $1 b$ & A & $79 \%$ & -- \\
\hline 6 & $1 b$ & $\mathrm{~B}(20 \mathrm{~h})^{d}$ & $74 \%$ & -- \\
\hline 7 & 1c & $\mathrm{B}(20 \mathrm{~h})$ & $81 \%$ & -- \\
\hline 8 & 1d & $\mathrm{B}(20 \mathrm{~h})$ & $53 \%^{e}$ & -- \\
\hline
\end{tabular}

$a_{5 \mathrm{~mol} \%}$ of the catalyst and 1.2 equiv. of 2 were employed.

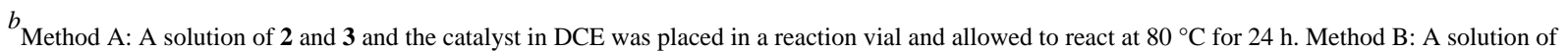
$\mathbf{2}$ in DCE was added slowly over the given time to a solution of $\mathbf{3}$ and the catalyst at $80^{\circ} \mathrm{C}$ and stirring was continued such that the total reaction time was $24 \mathrm{~h}$.

$c_{\text {Isolated yields. }}$

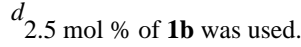

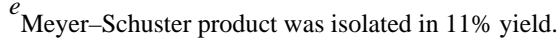




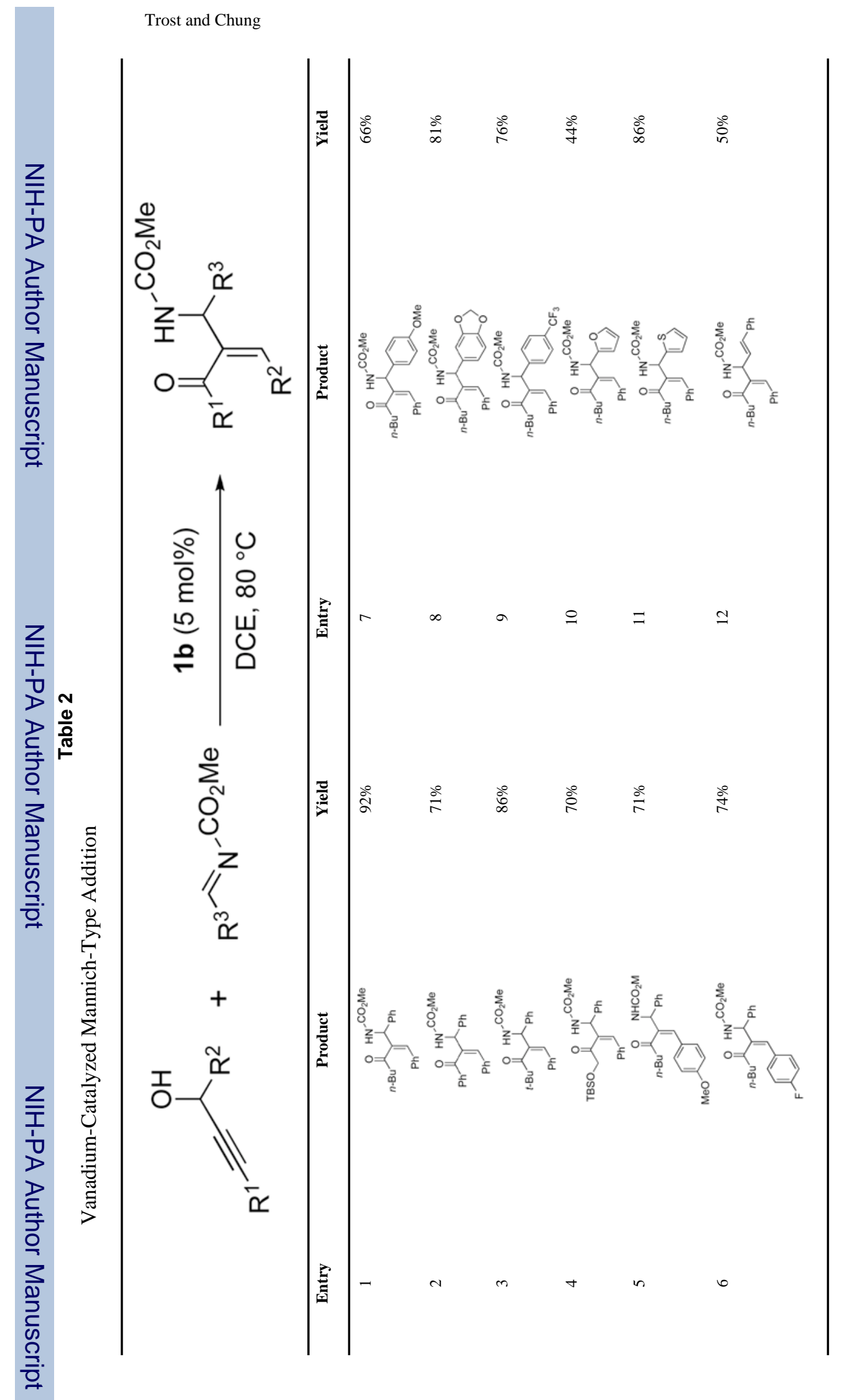

Page 7

J Am Chem Soc. Author manuscript; available in PMC 2008 September 4. 